\title{
1-metil-4-fenil-1,2,3,6-tetrahidropiridinin (MPTP) Parkinson hastalı̆̆ı üzerindeki etkileri
}

\author{
Effects of 1-methyl-4-phenyl-1,2,3,6-tetrahydropyridine on Parkinson's disease
}

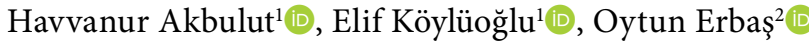 \\ ${ }^{1}$ Biruni Üniversitesi Tip Fakültesi Öğrencisi, İstanbul, Türkiye \\ ${ }^{2}$ Demiroğlu Bilim Üniversitesi Tip Fakültesi Fizyoloji Anabilim Dalı, İstanbul, Türkiye
}

\begin{abstract}
öz
Parkinson hastalığı erişkinlerde sık görülen, dopaminerjik nöronların zarar görmesi sonucunda gelişen kronik bir hareket bozukluğudur. Belirtileri tremor, rijidite, denge bozukluğu ve bradikinezidir. Hastalığın mevcut ilaçları semptomları tedavi eder; hiçbiri nörodejenerasyonu durdurmaz. Parkinson hastalığı araştırmaları için deney hayvanları üzerinde çeşitli modellemeler yapılır. Bu modellemelerde kullanılan maddelerin başında sentetik bir toksin olan 1-metil-4-fenil-1,2,3,6-tetrahidropiridin (MPTP) gelir. MPTP, yasadışı uyuşturucu üretimi sırasında istemeden ortaya çıkmış nörotoksik bir maddedir. MPTP, vücutta 1-metil-4-fenil-4-propiyonoksipiperidine dönüşür. Bu madde Parkinson hastalı̆̆na benzer biyokimyasal, patolojik ve klinik özelliklerin çoğunu akut ve geri dönüşümsüz bir şekilde meydana getirir ve bu deneysel Parkinson modeli birçok araştırmacıya yol gösterir. Bu derlemede, MPTP'nin keşfi, metabolizması, nörodejenerasyon mekanizmaları ve tedavide kullanımı literatür ışı̆̆ında tartışıldı.

Anahtar sözcükler: 1-metil-4-fenil-1,2,3,6-tetrahidropiridin, 1-metil-4-fenil-4-propiyonoksipiperidin, deneysel Parkinson modeli, Parkinson hastalığı.
\end{abstract}

\begin{abstract}
Parkinson's disease is a chronic movement disorder seen frequently in adults and caused by the destruction of dopaminergic neurons. Its symptoms are tremor, rigidity, balance disorder, and bradykinesia. The current medications of the disease cure the symptoms; none of them stops neurodegeneration. Various modellings are performed on experimental animals for Parkinson's disease research. The main substance used in these modellings is 1-methyl4-phenyl-1,2,3,6-tetrahydropyridine (MPTP), a synthetic toxin. MPTP is a neurotoxic agent that appeared unintentionally during the production of illicit drugs. MPTP converts to 1-methyl-4-phenyl-4-propionoxypiperidine in the body. This substance produces most of the biochemical, pathological, and clinical features similar to Parkinson's disease in an acute and irreversible way and this experimental Parkinson model leads many researchers. In this review, we discussed MPTP's discovery, metabolism, neurodegeneration mechanisms, and use in treatment in light of the literature.

Keywords: 1-methyl-4-phenyl-1,2,3,6-tetrahydropyridine, 1-methyl-4-phenyl-4-propionoxypiperidine, experimental Parkinson model, Parkinson's disease.
\end{abstract}

\section{TANIMLAMALAR}

\section{Parkinson hastalı̆̆}

Parkinson hastalı̆̆ı (PH) 1817 yılında İngiliz hekim James Parkinson tarafindan "shaking palsy" (titrek felç) adı altında tanımlanmıştır. Temelde substantia nigradaki dopaminerjik nöronların ölümünden kaynaklanmaktadır. Normal olarak insan beyninde belli bölgelerde dopamin üreten beyin hücreleri (nöronlar) bulunur. $\mathrm{Bu}$ hücreler beynin substantia nigra adı verilen belli bir alanında yoğunlaşmış halde bulunurlar. Dopamin, substantia nigra ile vücut hareketlerini kontrol eden diğer beyin bölgeleri arasındaki mesaj ileten bir kimyasaldır. Dopamin üreten hücrelerin \%60-80'i kayba uğradığından yeterli miktarda dopamin üretilmez, sağ kalan hücrelerde de Lewy cisimcikleri saptanır ve Parkinson hastalı̆̆ının motor belirtileri ortaya çıar (Şekil 1). Beyin hücrelerindeki bu yetersizlik süreci nörodejenerasyon olarak adlandırılır. Mevcut Parkinson hastalığı ilaçları semptomları tedavi

Geliş tarihi: 31 Ocak 2019 Kabul tarihi: 06 Ocak 2019 Online Yayın: 18 Şubat 2019

İletişim adresi: Elif Köylüoğlu. Biruni Üniversitesi Tıp Fakültesi Öğrencisi, 34295 Küçükçekmece, İstanbul, Türkiye. Tel: 0537 - 4721262 e-posta: ekoyluoglu15@gmail.com 
eder; hiçbiri dopaminerjik nöron dejenerasyonunu durdurmaz veya geciktirmez. ${ }^{[1,2]}$

\section{1-metil-4-fenil 1,2,3,6 tetrahidropiridin (MPTP)}

Parkinson hastalığının çevredeki bir zehirden kaynaklanabileceği kuramı son dönemlerde önem kazanmıştır. Bazı kimyasalların Parkinson hastalığına neden olabileceğine dair kanıtlar vardır. Bunların başında sentetik bir toksin olan MPTP gelmektedir. Bazı çalışmalarda kuyu suyu kullanımı, kırsal yaşam ve tarımda kullanılan bazı ilaçlara maruz kalan kişilerde de Parkinson hastalığına yakalanma riskinin arttığ gösterilmiştir.

MPTP, 1980'lerin başında ABD'nin California eyaletinde laboratuvarda uyuşturucu madde üreten bir kimyacının 1-metil-4-fenil-4propiyonoksipiperidin (MPPP) adlı uyuşturucu maddeyi bireşimlerken istemeden elde ettiği katışık bir yapay uyuşturucudur. Bu tür uyuşturucu kullanan kişilerden MPTP bulaşmış MPPP kullanan bir grup insanda geriye dönüşü olmayan ve Parkinson hastalığına çok benzeyen bir sendrom oluşturmuştur.

İnsanlarda ve maymunlarda MPTP, titreme, sertlik, hareket yavaşlığı, postural instabilite ve donma dahil olmak üzere PH'nin tüm özellikleri ile karakterize edilen geri dönüşümsüz ve şiddetli bir Parkinson sendromu oluşturur. Sendromun PH'den tek farkı hızlı başlayıp çok şiddetli seyretmesidir. MPTP, vücutta sinirleri etkileyen 1-metil-4-fenilpiridinyum (MPP+) adli zehre dönüşür. $\mathrm{Bu}$ zehir $\mathrm{PH}$ 'de beyin ve sinirlerde oluşan zedelenmenin aynısına yol açar. Aynı şekilde MPTP'ye duyarlllik hem maymunlarda hem de farelerde yaşla birlikte artar. Buna dayanarak yeni ilaçların etkisini maymunlar üzerinde değerlendirmeye yönelik çalışmalar yapilmaktadır. ${ }^{[3]}$

\section{ETYOPATOGENEZ}

Uyuşturucu bağımlıları tarafından yanlışlıkla kendi kendine tatbik edildikten sonra MPTP toksisitesi nasıl keşfedildi?

Genç uyuşturucu kullanıcıları 1982'de, narkotik meperidin (Demerol)'in bir analoğu olan MPPP'nin bir sokak preparasyonunun intravenöz kullanımına bağlı olarak hızla ilerleyen bir Parkinson sendromu geliştirmişlerdir. MPTP,
MPPP'nin yasadışı sentezi sırasında üretilen sorumlu nörotoksik kirleticidir.

MPTP kullanan insanlarda, beyin omurilik sıvısı (BOS)'nda düşük homovalinik asit (HVA) konsantrasyonları, levodopaya olumlu yanit ve tıbbi tedaviye uzun vadeli motor komplikasyonların gelişmesi, Parkinson hastalarında görülen ile hemen hemen aynıdır. Benzer şekilde, MPTP, insan dışı primatlarda PH'ye benzer biyokimyasal, patolojik ve klinik özelliklerin çoğunu indükler. ${ }^{[4-6]}$ Parkinson hastalığı ve MPTP ile ilişkili nöropatolojileri arasındaki karşılaştırmaya ilişkin veriler büyük ölçüde maymunlardaki MPTP çalışmalarından kaynaklanmaktadır, ${ }^{[7]}$ çünkü sadece dört insan MPTP olgusu otopsiye gelmiștir. ${ }^{[8,9]}$ Bu çalışmalar, PH'de olduğu gibi, düşük doz MPTP ile muamele edilmiş maymunların kaudat dopaminerjik sinir terminallerine karşı putamenal tercihlidejenerasyon sergilediklerini göstermektedir. ${ }^{[10]}$ Benzer şekilde, MPTP, substantia nigra pars compacta (SNPC)'da ventral tegmental alan (VTA)'dan nispeten daha fazla hücre kaybı ve SNPC'nin ventral ve lateral bölümlerinde tercih edilen bir nöron kaybı ve SNPC'nin ventral ve lateral bölümlerinde tercih edilen bir nöron kaybı da dahil olmak üzere, PH'de görülene benzer bir düzende dopaminerjik yolaklara zarar verir. ${ }^{[11,12]}$ Aynı zamanda, PH'yi hatırlatan, ${ }^{[13]}$ nöromelanin içeren dopaminerjik nöronlar, MPTP kaynaklı dejenerasyona daha duyarlıdır. ${ }^{[14]}$ Nöromelanin, pigmente edilmiş nöronlarda selektif olarak demir ile etkileşimi yoluyla reaktif oksijen türleri (ROS) oluşumunu katalize ederek $\mathrm{PH}$ ve MPTP ile muamele edilmiş maymunlarda nörodejenerasyona katkıda bulunabilir. ${ }^{[15]}$ Çeşitli organik moleküller, pestisitler, MPTP ve MPP de dahil olmak üzere nöromelanin ile etkileşime girer, ${ }^{[16]}$ bu yüzden toksik bileşikler için depo görevi görerek pigmentli nöronların toksisitesine katkıda bulunabilir.

Maymun MPTP modeli PH'nin iki karakteristik özelliğini içermez. İlk olarak nöronlar, tipik bir PH özelliği olan locus coeruleus gibi diğer monaminerjik çekirdeklerden sürekli olarak kaybolmaz. ${ }^{[7,17]}$ İkincisi, Lewy cisimciklerine benzeyen intraneuronal inklüzyonlar tanımlanmış olmasına rağmen, ${ }^{[17]}$ klasik Lewy cisimcikleri, MPTP ile indüklenmiş hastaların veya maymunların beyninde ikna edici olarak gösterilmemiştir. ${ }^{[7]}$ Lewy cisimciği benzeri oluşum eksikliği, bu durumlarda dopaminerjik nöronların hızla yaralandığı gerçeğini yansıtabilir. ${ }^{[18]}$ 
Bu nöropatolojik eksikliklere rağmen, maymun MPTP modeli, PH semptomlarının tedavisinde yeni stratejilerin ve ajanların değerlendirilmesinde altın standarttır. Örneğin, MPTP maymunlarının elektrofizyolojik çalışmaları, subtalamik çekirdeğin hiperaktivitesinin, $\mathrm{PH}$ motor disfonksiyonunun oluşumunda anahtar bir faktör olduğunu ortaya koymuştur. ${ }^{[19]} \mathrm{Bu}$ seminal keşif, semptomları medikal tedavi ile daha da iyileştirilemeyen $\mathrm{PH}$ hastalarının motor fonksiyonlarını etkin bir şekilde iyileştirmek için kronik yüksek frekanslı stimülasyon prosedürlerini (ayrıca derin beyin stimülasyonu olarak da adlandırılır) kullanarak bu yapının hedeflenmesini sağlamıştır. ${ }^{[20]} \mathrm{Ek}$ olarak, glial türevli nörotrofik faktörün (GDNF) verilmesinin hem MPTP ile indüklenmiş nigrostriatal dopaminerjik nörodejenerasyonu önemli ölçüde sınırladığını göstermek için MPTP ile muamele edilmiş maymunlar kullanılmıştır. ${ }^{[21,22]}$ Pratik düşünceler nedeniyle, MPTP maymunları genellikle dopaminerjik nörodejenerasyonun moleküler mekanizmalarını araştırmak için kullanılmamıştır; MPTP fare modeli tipik olarak bu tür çalışmalar için kullanılır.

\section{MPTP metabolizması ve PH nörodejenerasyon seçiciliği}

MPTP'nin neden olduğu parkinsonizmin ilk keşfedilmesinden bu yana, Şekil 2'de gösterildiği gibi, bu toksin tarafından kullanılan moleküler yol hakkında çok şey öğrenilmiştir. Önemli olarak, bu bilgi araştırmacıların PH genlerinin işlevlerini araştırmak için MPTP'yi biyolojik bir prob olarak kullanmalarını sağlar ve dopaminerjik nöronların nörodejenerasyonu sirasında meydana gelen moleküler olayları inceler. Örneğin, PH genleri (veya dopaminerjik nöronal ölümle muhtemel olan diğer genler) için mutant farelere MPTP enjekte edilebilir ve bu fareler belirgin bir şekilde artırılmış veya bastırılmış dopaminerjik nöronal ölüm gösterdiğinde, bilinen moleküler hedeflerinden hangisinin araştırılabileceği MPTP ile değişmiştir.

Sistemik uygulamadan sonra, oldukça lipofilik olan MPTP kan-beyin bariyerine kolayca nüfuz eder ve beyin hücrelerine girer. Amfifilik olduğu için asidik organellere, çoğunlukla lizozomlara, astrositlere yakalanır ve pro-toksin MPTP, sadece glia ve serotonerjik nöronlarda bulunan monoamin oksidaz B (MAO-B) enzimi ile 1-metil-4-fenil2,3-dihidropiridinyum (MPDP+)'a oksitlenir. Daha sonra, aktif toksik molekül olan MPP+'ya (muhtemelen kendiliğinden oksidasyon yoluyla) dönüştürülür ve bilinmeyen bir mekanizma ile hücre dışı boşluğa salınır (MPTP'nin kendisi toksik görünmemektedir, ancak oksitlenmiş ürünü MPP+ toksiktir). MPP+ polar bir molekül olduğundan, hücrelere girmek için plazma zarı taşıyıcılarına bağlıdır. MPP+, Dopamin taşıyıcıları ve ayrıca norepinefrin ve serotonin taşıyıcıları için yüksek afiniteli bir substrattır. ${ }^{\text {[23,24] }}$

Dopamin taşıyıcılarının farmakolojik inhibisyonu veya genetik olarak silinmesi, MPTP'nin neden olduğu dopaminerjik hasarı önler, ${ }^{[23,25]}$ MPTP nörotoksisitesinde bu adımın zorunlu karakterini gösterir. Bununla birlikte, Dopamin taşıyıcıları ile alım, MPTP'nin neden olduğu nigrostriatal dopaminerjik lezyonun seçiciliğini tamamen açıklamamaktadır. ${ }^{[26]}$

Nöronların içinde (Şekil 3), MPP+ en az üç yolu izleyebilir: (i) MPP+'yı sinaptozomal veziküllere dönüştüren veziküler monoamin taşıyı1-2'ye (VMAT2) bağlanabilir; ${ }^{[27]}$ (ii) mitokondriyal transmembran potansiyeline dayanan bir mekanizma ile mitokondri içinde konsantre edilebilir; ${ }^{[28]}$ ve (iii) sitozolik enzimler, özellikle negatif yük taşıyanlar ile etkileşime girip sitozolde kalabilir. ${ }^{[29]}$ Veziküler MPP+'nın sekestrasyonu, toksinleri sekestre ederek ve olası etki bölgesi olan mitokondriye erişmesini önleyerek hücreleri MPTP'nin neden olduğu nörodejenerasyondan koruyor gibi görünmektedir. Veziküler sekestrasyonun önemi, daha fazla VMAT2 yoğunluğunu eksprese etmek için transfekte edilen hücrelerin MPP+'ya duyarlı olanların MPP+'ya dirençli hücrelere ${ }^{[27]}$ ve heterozigot VMAT2 olmayanlara dönüştüğünü gösteren deneyler ile belirlenmiştir.

Fareler MPTP'nin neden olduğu nörodejenerasyona karşı duyarlılığı artırır.[30] Dopamin taşıyıcısının VMAT2'ye oranının hem PH'de hem de MPTP modelinde nöronal dejenerasyon olasılığını öngördüğüanlaşılmaktadır. Örneğin, hem MPTP hem de PH'den en fazla etkilenen putamenal dopaminerjik terminaller, kaudatta daha az etkilenenlerden daha yüksek bir Dopamin taşıyıcıs1/VMAT2 oranına sahiptir. ${ }^{[31]}$

\section{Nigrostriatal nörodejenerasyon mekanizmaları}

Mitokondrinin içine girdikten sonra MPP+, mitokondriyal elektron taşıma zincirinin 
multienzim kompleksi (kompleks I) inhibe ederek oksidatif fosforilasyonu bozar. ${ }^{[32]} \mathrm{Bu}$ blokajın iki sitotoksik sonucu vardır. Birincisi, ATP oluşumunu bozar, iyon nakli gibi enerjiye bağlı işlemlerin engellenmesine, doku ATP içeriğinde, özellikle striatum ve ventral midbrainde hizla azalmaya neden olur. ${ }^{[33,34]}$ Son zamanlarda yapilan bir araştırma, kompleks I'in inhibisyonunun sadece hücre ölümünü ortaya çıkarmakla ilgili olmadığını göstermektedir. Gerçekten de, kalsiyum iyonu homeostazının bozulması MPP+ toksisitesinde hayati bir rol oynar. $\mathrm{Bu}$, hücre içi kalsiyum iyonlarının $(\mathrm{Ca} 2+)$ yükselmesine neden olur, $\mathrm{Ca} 2+$ bağıml enzimlerin, örneğin normal hücre fonksiyonunu bozan ve hücre hasarına neden olan protein kinaz ve kalpain I ve II'nin aktivasyonuna yol açar. Parkinson hastalığında gözlenen kompleks I aktivitesindeki küçük değişiklikler bile, sinaptik mitokondri bakımından zengin olan dopaminerjik sinir terminallerine özellikle zararl olabilir. İkincisi, MPP+ oksidatif stres oluşumunu desteklemektedir. Bu kavram, reaktif oksijen radikallerinin ve serbest demirin üretilmesi ile gösterilmiştir. MPP+, elektronların kompleks I içinden akışını engelleyerek özellikle süperoksitin ROS üretimini uyarabilir. ${ }^{[35,36]}$ Maymunlarda MPP+'nın, Fenton reaksiyonu yoluyla hidrojen peroksit ile reaksiyona girebileceği ve dolayısıyla hidroksil radikallerini $(\bullet \mathrm{OH})$ verdiği toksik demiri (II) $(\mathrm{Fe} 2+)$ saldığ ROS'ler ve $\mathrm{Fe} 2+$, PH'nin patogenezinde güçlü bir şekilde yer almıştır. Daha önemlisi, MPTP, PH'de bir başka temel nigral biyokimyasal değişikliği, yani kemirgenlerde gözlendiği gibi glutatyon içeriğinin azalmasını taklit eder. Enerji metabolizmasında değişiklikler ve aşırı nöronal ölümden günler önce, MPTP uygulamasının saatleri içinde ROS pikinin oluşumu meydana gelir. ${ }^{[37]} \mathrm{Bu}$ nedenle, bu ilk olayların çoğu hücreyi doğrudan öldürmesi muhtemel değildir, daha ziyade çoğu dopaminerjik nöronları öldüren hücresel olaylardır. ${ }^{[38-40]}$ Farelere düşük ila orta MPTP dozlarının uzun süreli uygulanması, SNPC dopaminerjik nöronların morfolojik olarak tanımlanmış apoptozisine yol açar. ${ }^{[11]}$ Tümör baskılayıc1 protein p53, Bax ekspresyonunu düzenlediği bilinen az sayıdaki molekülden biridir ve DNA hasarı ile aktive edilir. Ayrıca, p53'ün farmakolojik inhibisyonu, MPTP'nin neden olduğu Bax artışını ve ardından gelen SNPC dopaminerjik nöron ölümünü zayiflatır $^{[42]}$ ve p53 olmayan fareleri, MPTP kaynaklı nörodejenerasyona karşı dirençlidir. ${ }^{[43,44]}$

\section{MPTP'nin PH'nin mekanizmasının anlaşılmasında kullanımı}

Nigrostriatal dopamin nöronlarının MPTP toksisitesine seçici duyarllı̆ğı ve sonuçta ortaya çıkan klinik sendromun PH'ye benzerliği, PH'nin gelişimine katkıda bulunan etyolojik faktörlerin belirlenmesine dikkat çekmiştir.

Parkinson hastalığı insanları nörodejenerasyona maruz bırakır. Genel nüfusta 65 yaş üstü kişilere zarar vermiştir. Etkili bir tedavi stratejisi geliştirmek için insan PH'sini taklit eden insan dişı bir primat (NHP) $\mathrm{PH}$ modeli gereklidir. Kronik $\mathrm{PH}$ semptomlarını koruyan NHP modelleri, $\mathrm{PH}$ patogenezinin ve terapötik gelişim ajanların altında yatan mekanizmaların translasyonel bir çalışmasını oluşturmak için esastır. ${ }^{[45]}$ MPTP, NHP'lerde, PH'li insan hastalara, diğer hayvanlardan daha fazla benzerlik gösteren PDP'nin temel semptomlarını üretmek için kullanılır. ${ }^{[46-49]}$ Son zamanlarda yapilan araştırmalar, pozitron emisyon tomografisi (PET) görüntülemesine göre, SNPC ve striatumdaki dopa-minerjik nöronal sistemlerin MPTP tedavisi ile zarar gördüğünü bildirmiştir. ${ }^{\text {50-52] }}$

MPTP tedavisindeki ayarlamaları hesaplamak için $\mathrm{PH}$ semptomlarının bireysel şiddetini yansitan hedef kriterleri belirlemek gereklidir. İyi çalışmalarda, otomatik video görüntü analiz sistemi, parkinsonian sinomolgus maymununda lokomosyon davranışı için hassas bir objektif ölçüm yöntemi olarak doğrulanmış ve MPTP tarafından uyarılan PH modelleri için davranışsal nicelemeyi ölçmek için kullanılmıştır. Bununla birlikte, MPTP ayarlamalarının bireysel ciddiyeti için objektif kriterler sunulmamıştır.

Parkinson davranış analizi: Maymunların davranışları, Kurlan skalası kullanılarak toplam 240 dakikalık bir süre boyunca yapılan video kaydının analizi ile maymun $\mathrm{PH}$ modelleri için derecelendirme ölçeğine göre değerlendirilmiştir. ${ }^{[53,54]}$

$\mathrm{Bu}$ skala: yüz ifadesi (0-3); dinlenme tremoru (0-3); eylem ya da niyet titremesi (0-3); duruş (0-2); yürüyüş (0-3); bradikinezi (0-4); denge koordinasyonu (0-3); üst ekstremite $(0-3)$ ve alt ekstremite (0-3) kaba motor becerileri ve savunma gücü $(0-2) .{ }^{[55]}$ 
Bununla birlikte, PH'de MPTP tarafından uyarılmayan bazı temel değişiklikler vardır. Sonuç olarak, bu, PH'ye MPTP benzeri toksinlerin dahil edilmesine dair bazı şüpheler doğurmuştur. Nitekim, insanlık dışı primatlarda ve kemirgenlerde, PH'nin patolojik özelliklerinin, yani Lewy cisimlerinin ortaya çıktığına dair hiçbir kanıt bulunamamıştır. Parkinson hastalığının en belirgin klinik özelliklerinden biri olan dinlenme tremoru, MPTP'nin neden olduğu parkinsonizmde nadiren görülür. Nigral nöronların nörodejenerasyonu ve PH klinik semptomlarının tezahürü ilericidir. Buna karşılık, MPTP'ye maruz kalma sonrası PH'ye benzer semptomların gelişimi akuttur. Parkinson hastalığında, suffia innominata'nın kolinerjik hücreleri, nöronal kayıp ve Lewy cisimcikleri patolojisi için kanıt gösterirken, MPTP bu değişiklikleri ortaya çıkarmaz. Bu çeşitliliklerden bazıları tür farklıllklarına dayanabilir; Bununla birlikte, PH'de ve MPTP'de hücre ölümüne neden olan mekanizmalarda bir sapma olduğu öne sürülür.

Sonuç olarak, MPTP, aktif olarak kullanılan birçok dopaminerjik nörotoksin geliştirmiş olmasına rağmen, PH'yi araştırmak için "en iyi" model olmaya devam etmektedir. Ek olarak, MPTP senaryosunun, hastalığın altta yatan olası patogenezi çözme arayışı üzerinde büyük etkisi olmuştur. Parkinson hastalığındaki dopaminerjik nöronların dejenere olabileceği olası bir mekanizma/mekanizmalar sağlamıştır. Ek olarak, hastalığın nigral hücre ölümü karakteristiğini ortaya çıkarmada rol oynayabilecek bazı endojen veya eksojen nörotoksin arayışını tetiklemiştir. $\mathrm{Bu}$ nörotoksinlerin bazıları, 6-hidroksidopamin, demir ve metamfetamin içerir. ${ }^{[44]}$

\section{Çıkar çakışması beyanı}

Yazarlar bu yazının hazırlanması ve yayınlanması aşamasında herhangi bir çıkar çakışması olmadığını beyan etmişlerdir.

\section{Finansman}

Yazarlar bu yazının araştırma ve yazarlık sürecinde herhangi bir finansal destek almadıklarını beyan etmişlerdir.

\section{KAYNAKLAR}

1. Türkiye Parkinson Hastalığı Derneği. Available from: http://parkinsondernegi.com/parkinson-nedir/

2. Murat K. Available from: http://norolojiklinigi.info/ parkinson-hastaligi/
3. Available from: http://www.saglik.im/parkinsonhastaligi/

4. Rose S, Nomoto M, Jackson EA, Gibb WR, Jaehnig $P$, Jenner $P$, et al. Age-related effects of 1-methyl-4-phenyl-1,2,3,6-tetrahydropyridine treatment of common marmosets. Eur J Pharmacol 1993;230:177-85.

5. Irwin I, DeLanney LE, Langston JW. MPTP and aging. Studies in the C57BL/6 mouse. Adv Neurol 1993;60:197-206.

6. Ovadia A, Zhang Z, Gash DM. Increased susceptibility to MPTP toxicity in middle-aged rhesus monkeys. Neurobiol Aging 1995;16:931-7.

7. Forno LS, DeLanney LE, Irwin I, Langston JW. Similarities and differences between MPTPinduced parkinsonsim and Parkinson's disease. Neuropathologic considerations. Adv Neurol 1993;60:600-8.

8. Davis GC, Williams AC, Markey SP, Ebert MH, Caine ED, Reichert CM, et al. Chronic Parkinsonism secondary to intravenous injection of meperidine analogues. Psychiatry Res 1979;1:249-54.

9. Langston JW, Forno LS, Tetrud J, Reeves AG, Kaplan JA, Karluk D. Evidence of active nerve cell degeneration in the substantia nigra of humans years after 1-methyl-4-phenyl-1,2,3,6-tetrahydropyridine exposure. Ann Neurol 1999;46:598-605.

10. Moratalla R, Quinn B, DeLanney LE, Irwin I, Langston JW, Graybiel AM. Differential vulnerability of primate caudate-putamen and striosome-matrix dopamine systems to the neurotoxic effects of 1-methyl-4-phenyl1,2,3,6-tetrahydropyridine. Proc Natl Acad Sci U S A 1992;89:3859-63.

11. Sirinathsinghji DJ, Kupsch A, Mayer E, Zivin M, Pufal D, Oertel WH. Cellular localization of tyrosine hydroxylase mRNA and cholecystokinin mRNAcontaining cells in the ventral mesencephalon of the common marmoset: effects of 1-methyl-4-phenyl1,2,3,6-tetrahydropyridine. Brain Res Mol Brain Res 1992;12:267-74.

12. Varastet M, Riche D, Maziere M, Hantraye P. Chronic MPTP treatment reproduces in baboons the differential vulnerability of mesencephalic dopaminergic neurons observed in Parkinson's disease. Neuroscience 1994;63:47-56.

13. Hirsch E, Graybiel AM, Agid YA. Melanized dopaminergic neurons are differentially susceptible to degeneration in Parkinson's disease. Nature 1988;334:345-8.

14. Herrero MT, Hirsch EC, Kastner A, Ruberg M, Luquin MR, Laguna J, et al. Does neuromelanin contribute to the vulnerability of catecholaminergic neurons in monkeys intoxicated with MPTP? Neuroscience 1993;56:499-511.

15. Zecca L, Tampellini D, Gerlach M, Riederer P, Fariello RG, Sulzer D. Substantia nigra neuromelanin: structure, synthesis, and molecular behaviour. Mol Pathol 2001;54:414-8. 
16. D'Amato RJ, Lipman ZP, Snyder SH. Selectivity of the parkinsonian neurotoxin MPTP: toxic metabolite MPP+ binds to neuromelanin. Science 1986;231:987-9.

17. Forno LS, Langston JW, DeLanney LE, Irwin I, Ricaurte GA. Locus ceruleus lesions and eosinophilic inclusions in MPTP-treated monkeys. Ann Neurol 1986;20:449-55.

18. Betarbet R, Sherer TB, MacKenzie G, Garcia-Osuna M, Panov AV, Greenamyre JT. Chronic systemic pesticide exposure reproduces features of Parkinson's disease. Nat Neurosci 2000;3:1301-6.

19. Bergman H, Wichmann T, DeLong MR. Reversal of experimental parkinsonism by lesions of the subthalamic nucleus. Science 1990;249:1436-8.

20. Limousin P, Krack P, Pollak P, Benazzouz A, Ardouin $\mathrm{C}$, Hoffmann $\mathrm{D}$, et al. Electrical stimulation of the subthalamic nucleus in advanced Parkinson's disease. N Engl J Med 1998;339:1105-11.

21. Gash DM, Zhang Z, Ovadia A, Cass WA, Yi A, Simmerman L, et al. Functional recovery in parkinsonian monkeys treated with GDNF. Nature 1996;380:252-5.

22. Kordower JH, Emborg ME, Bloch J, Ma SY, Chu Y, Leventhal L, et al. Neurodegeneration prevented by lentiviral vector delivery of GDNF in primate models of Parkinson's disease. Science 2000;290:767-73.

23. Javitch JA, D'Amato RJ, Strittmatter SM, Snyder $\mathrm{SH}$. Parkinsonism-inducing neurotoxin, N-methyl4-phenyl-1,2,3,6 -tetrahydropyridine: uptake of the metabolite N-methyl-4-phenylpyridine by dopamine neurons explains selective toxicity. Proc Natl Acad Sci U S A 1985;82:2173-7.

24. Mayer RA, Kindt MV, Heikkila RE. Prevention of the nigrostriatal toxicity of 1-methyl-4-phenyl1,2,3,6-tetrahydropyridine by inhibitors of 3,4-dihydroxyphenylethylamine transport. J Neurochem 1986;47:1073-9.

25. Bezard E, Gross CE, Fournier MC, Dovero S, Bloch $\mathrm{B}$, Jaber M. Absence of MPTP-induced neuronal death in mice lacking the dopamine transporter. Exp Neurol 1999;155:268-73.

26. Haber SN, Ryoo H, Cox C, Lu W. Subsets of midbrain dopaminergic neurons in monkeys are distinguished by different levels of mRNA for the dopamine transporter: comparison with the mRNA for the $\mathrm{D} 2$ receptor, tyrosine hydroxylase and calbindin immunoreactivity. J Comp Neurol 1995;362:400-10.

27. Liu Y, Roghani A, Edwards RH. Gene transfer of a reserpine-sensitive mechanism of resistance to N-methyl-4-phenylpyridinium. Proc Natl Acad Sci U S A 1992;89:9074-8.

28. Ramsay RR, Singer TP. Energy-dependent uptake of N-methyl-4-phenylpyridinium, the neurotoxic metabolite of 1-methyl-4-phenyl-1,2,3,6tetrahydropyridine, by mitochondria. J Biol Chem 1986;261:7585-7.

29. Klaidman LK, Adams JD Jr, Leung AC, Kim SS, Cadenas E. Redox cycling of MPP+: evidence for a new mechanism involving hydride transfer with xanthine oxidase, aldehyde dehydrogenase, and lipoamide dehydrogenase. Free Radic Biol Med 1993;15:169-79.

30. Takahashi N, Miner LL, Sora I, Ujike H, Revay RS, Kostic V, et al. VMAT2 knockout mice: heterozygotes display reduced amphetamine-conditioned reward, enhanced amphetamine locomotion, and enhanced MPTP toxicity. Proc Natl Acad Sci U S A 1997;94:9938-43.

31. Miller GW, Gainetdinov RR, Levey AI, Caron MG. Dopamine transporters and neuronal injury. Trends Pharmacol Sci 1999;20:424-9.

32. Nicklas WJ, Vyas I, Heikkila RE. Inhibition of NADHlinked oxidation in brain mitochondria by 1-methyl4-phenyl-pyridine, a metabolite of the neurotoxin, 1-methyl-4-phenyl-1,2,5,6-tetrahydropyridine. Life Sci 1985;36:2503-8.

33. Chan P, DeLanney LE, Irwin I, Langston JW, Di Monte D. Rapid ATP loss caused by 1-methyl-4phenyl-1,2,3,6-tetrahydropyridine in mouse brain. $\mathrm{J}$ Neurochem 1991;57:348-51.

34. Fabre E, Monserrat J, Herrero A, Barja G, Leret ML. Effect of MPTP on brain mitochondrial H2O2 and ATP production and on dopamine and DOPAC in the striatum. J Physiol Biochem 1999;55:325-31.

35. Takubo $\mathrm{H}$, Kondo $\mathrm{T}$, Mori $\mathrm{H}$, Miyake $\mathrm{T}$, Suda $\mathrm{K}$, Yokochi M, et al. A 62-year-old man with familial parkinsonism with the onset at 24 years of the age. No To Shinkei 1996;48:587-97. [Abstract]

36. Hasegawa E, Kang D, Sakamoto K, Mitsumoto A, Nagano T, Minakami S, et al. A dual effect of 1-methyl-4-phenylpyridinium (MPP+)-analogs on the respiratory chain of bovine heart mitochondria. Arch Biochem Biophys 1997;337:69-74.

37. Jackson-Lewis V, Jakowec M, Burke RE, Przedborski $\mathrm{S}$. Time course and morphology of dopaminergic neuronal death caused by the neurotoxin 1-methyl-4-phenyl-1,2,3,6-tetrahydropyridine. Neurodegeneration 1995;4:257-69.

38. Mandir AS, Przedborski S, Jackson-Lewis V, Wang ZQ, Simbulan-Rosenthal CM, Smulson ME, et al. Poly(ADP-ribose) polymerase activation mediates 1-methyl-4-phenyl-1, 2,3,6-tetrahydropyridine (MPTP)-induced parkinsonism. Proc Natl Acad Sci U S A 1999;96:5774-9.

39. Saporito MS, Thomas BA, Scott RW. MPTP activates c-Jun $\mathrm{NH}(2)$-terminal kinase (JNK) and its upstream regulatory kinase $\mathrm{MKK} 4$ in nigrostriatal neurons in vivo. J Neurochem 2000;75:1200-8.

40. Vila M, Jackson-Lewis V, Vukosavic S, Djaldetti R, Liberatore G, Offen D, et al. Bax ablation prevents dopaminergic neurodegeneration in the 1-methyl4-phenyl-1,2,3,6-tetrahydropyridine mouse model of Parkinson's disease. Proc Natl Acad Sci U S A 2001;98:2837-42.

41. Tatton NA, Kish SJ. In situ detection of apoptotic nuclei in the substantia nigra compacta of 1-methyl4-phenyl-1,2,3,6-tetrahydropyridine-treated 
mice using terminal deoxynucleotidyl transferase labelling and acridine orange staining. Neuroscience 1997;77:1037-48.

42. Duan W, Zhu X, Ladenheim B, Yu QS, Guo Z, Oyler $\mathrm{J}$, et al. p53 inhibitors preserve dopamine neurons and motor function in experimental parkinsonism. Ann Neurol 2002;52:597-606.

43. Trimmer PA, Smith TS, Jung AB, Bennett JP Jr. Dopamine neurons from transgenic mice with a knockout of the p53 gene resist MPTP neurotoxicity. Neurodegeneration 1996;5:233-9.

44. Siegel GJ, Agranoff BW, Albers RW, Fisher SK, Uhler MD, editors. Basic Neurochemistry: Molecular, Cellular and Medical Aspects. 6th ed. Philadelphia: Lippincott-Raven; 1999.

45. Emborg ME. Nonhuman primate models of Parkinson's disease. ILAR J 2007;48:339-55.

46. Blandini F, Armentero MT. Animal models of Parkinson's disease. FEBS J 2012;279:1156-66.

47. Morin N, Jourdain VA, Di Paolo T. Modeling dyskinesia in animal models of Parkinson disease. Exp Neurol 2014;256:105-16.

48. Porras G, Li Q, Bezard E. Modeling Parkinson's disease in primates: The MPTP model. Cold Spring Harb Perspect Med 2012;2:a009308.

49. Przedborski S, Jackson-Lewis V, Naini AB, Jakowec $\mathrm{M}$, Petzinger $\mathrm{G}$, Miller $\mathrm{R}$, et al. The parkinsonian toxin 1-methyl-4-phenyl-1,2,3,6-tetrahydropyridine (MPTP): a technical review of its utility and safety.
J Neurochem 2001;76:1265-74.

50. Ashkan K, Wallace BA, Mitrofanis J, Pollo C, Brard PY, Fagret D, et al. SPECT imaging, immunohistochemical and behavioural correlations in the primate models of Parkinson's disease. Parkinsonism Relat Disord 2007;13:266-75.

51. Liu Y, Yue F, Tang R, Tao G, Pan X, Zhu L, et al. Progressive loss of striatal dopamine terminals in MPTP-induced acute parkinsonism in cynomolgus monkeys using vesicular monoamine transporter type 2 PET imaging ([(18)F]AV-133). Neurosci Bull 2014;30:409-16.

52. Nagai Y, Obayashi S, Ando K, Inaji M, Maeda J, Okauchi $\mathrm{T}$, et al. Progressive changes of pre- and postsynaptic dopaminergic biomarkers in conscious MPTPtreated cynomolgus monkeys measured by positron emission tomography. Synapse 2007;61:809-19.

53. Imbert C, Bezard E, Guitraud S, Boraud T, Gross CE. Comparison of eight clinical rating scales used for the assessment of MPTP-induced parkinsonism in the Macaque monkey. J Neurosci Methods 2000;96:71-6.

54. Kurlan R, Kim MH, Gash DM. Oral levodopa doseresponse study in MPTP-induced hemiparkinsonian monkeys: assessment with a new rating scale for monkey parkinsonism. Mov Disord 1991;6:111-8.

55. Seo J, Lee Y, Kim BS, Park J, Yang S, Yoon HJ, et al. A non-human primate model for stable chronic Parkinson's disease induced by MPTP administration based on individual behavioral quantification. J Neurosci Methods 2019;311:277-87. 